Mirai. Estudios Japoneses

ISSN-e: 1988-2378

http://dx.doi.org/10.5209/MIRA.57117

\title{
Marco jurídico del Plan Nacional para el Desarrollo del Turismo en Japón de 2012: Activando el turismo internacional
}

\author{
Dra. Carmen Tirado Robles ${ }^{1}$
}

Resumen: La Ley básica de turismo de 1963, fue reformada el 13 de diciembre de 2006 con la aprobación por parte de la Dieta japonesa de una Ley básica de promoción del turismo en Japón, que entró en vigor el 1 de enero de 2007 y que sitúa al turismo como uno de los pilares básicos de la política japonesa del siglo XXI. Esta Ley se desarrolla mediante el Plan Nacional para el desarrollo del Turismo en Japón que se aprueba por parte del Gobierno en 2012. Basándose en el artículo 10.4 de la Ley, se definen en el Plan básico una serie de medidas para ampliar y potenciar el turismo en Japón, tanto en lo que se refiere al turismo nacional como internacional, así como medidas para mejorar la calidad del turismo en el país.

En lo que se refiere al turismo internacional o de extranjeros, el objetivo para 2016 era alcanzar los 18 millones de visitantes y esto se intentaba lograr con una serie de medidas específicas dirigidas a los extranjeros que destacan en este planeamiento, las cuales vamos a analizar, con el fin de comprobar su efectividad para el logro de los objetivos del Plan. Los mercados a los que se dirigen estas medidas son, especialmente, los países del Sudeste de Asia y otros países emergentes, donde el crecimiento económico es notable, así como la Unión Europea, Estados Unidos y Australia, ya que en estos mercados es donde se planifican estancias más largas y donde los viajeros están más dispuestos a gastar mayores cantidades de dinero.

Palabras clave: Japón; turismo internacional; medidas de promoción; fortalezas; debilidades.

\section{[en] A legal framework in the 2012 National Plan for the development of tourism: activating international tourism}

\begin{abstract}
The 1963 Basic Law on Tourism was reformed in 2006, with the passing of a basic Law by the Japanese Diet to promote tourism in Japan, which entered into force on January 1st, 2007, and which places tourism as one of the pillars of Japanese politics in this century. This law was implemented by the National Plan for Development of Tourism in Japan that was approved by the Government in 2012. Based on Article $10.4^{\circ}$ of this Law, some measures are defined in the basic plan to expand and enhance tourism in Japan, both in regards to domestic and international tourism, as well as measures to improve the quality of tourism in the country.

With regards to international tourism, the goal for 2016 was to reach 18 million visitors and this has been attempted with specific measures aimed at foreigners which are very relevant in this planning, and will be analysed in order to prove their effectiveness in achieving the objectives of the Plan. The markets to which these measures are directed are, especially, the countries of Southeast Asia and other emerging countries, where economic growth is remarkable, together with the European Union, United States and Australia, since travellers coming from these markets plan longer stays and are more willing to spend larger amounts of money.
\end{abstract}

Keywords: Japan; international tourism; promotion measures; strengths; weaknesses.

Sumario. 1. El medio japonés por antonomasia. 2. El plan nacional de promoción del turismo. 1. Los resultados del Plan anterior. 2. Los objetivos de futuro del Plan de 2012. 3. Las medidas para mejorar la base del turismo centradas en el turismo internacional. 3. 1. La expansión y mejora del turismo internacional. 3. 2. Lograr un mayor nivel de satisfacción de los visitantes extranjeros. 3. 3.

Facultad de Derecho. Departamento de Derecho Público. Universidad de Zaragoza.

mctirado@unizar.es 
Incremento del número de conferencias celebradas. 3. 4. Incremento del número de japoneses que viajan al extranjero. 3. Conclusiones.

Cómo citar: Tirado Robles, C. (2017). Marco jurídico del Plan Nacional para el Desarrollo del Turismo en Japón de 2012: Activando el turismo internacional, en Mirai. Estudios Japoneses 1(2017), 263-277.

\section{Introducción}

La Ley básica del Turismo japonesa databa de 1963, por lo que era necesaria una revisión, que se produjo con la aprobación de una nueva ley por parte de la Dieta el 13 de diciembre de 2006 (ley 117/2006), ley que entra en vigor en enero de 2007. De esta Ley y de otras medidas legislativas de desarrollo derivarán una serie de iniciativas que vamos a estudiar desde un punto de vista jurídico, analizando sus fortalezas y debilidades, para poder responder a la pregunta de si han cumplido sus objetivos o no.

Hay que tener en cuenta que todas las medidas que vamos a analizar se desarrollan en Japón bajo del Gobierno de Hatoyama Yukio, que fue Primer ministro desde septiembre de 2009 hasta junio de 2010, un periodo breve que, sin embargo, se caracteriza por dar un impulso importante a la política de turismo japonesa. Bajo el liderazgo del Ministro Maehara Seiji, el Ministerio de Territorio, Infraestructuras, Transporte y Turismo (MLIT) puso las bases para que se llevase a cabo una de las siete líneas de la Estrategia de Crecimiento aprobada por el Gabinete el 18 de junio de 2010: "Convertirse en una nación turística". En diciembre de 2009 se había puesto en marcha, también a iniciativa del Gobierno, la Oficina de Promoción de una Nación Turística, con el Ministro Maehara a la cabeza y el establecimiento de una estructura unificada del gobierno para perseguir la construcción de una nación turística.

Efectivamente, la nueva Ley introduce una serie de cambios que implican situar al turismo como uno de los pilares de la política japonesa del siglo $\mathrm{XXI}^{2}$ :

- El título: se cambia a Ley fundamental de promoción del turismo de la nación indicando con ello que la promoción del turismo va a ser una estrategia nacional y que la Ley va a ser la herramienta para conseguir los objetivos fijados.

- En el preámbulo se establece que la promoción del turismo es una tarea clave y esencial para el desarrollo económico de la nación en el siglo XXI, teniendo en cuenta el pleno desarrollo y la trascendencia de los intercambios internacionales y la necesidad de superar una crisis económica cuyas consecuencias viene arrastrando Japón desde el siglo pasado. Hay que tener en cuenta que Japón, excepto en su historia reciente, ha sido un país extremadamente aislado, tanto por su carácter insular como por las políticas desarrolladas en ciertas épocas por sus gobernantes.

2 Una explicación somera en inglés de esta nueva Ley se encuentra en página web de la Agencia de Turismo japonesa (JTA), organismo dependiente del Ministerio de Territorio, Infraestructuras, Transporte y Turismo (http:// www.mlit.go.jp/kankocho/en/kankorikkoku/kihonhou.html), [Consulta: 24/2/2017]. 
- El objetivo de la Ley, por tanto, es promover una serie de medidas integrales y sistemáticas para el establecimiento de una nación turística y así contribuir al desarrollo económico, a la estabilidad del sistema y a la mejora del entendimiento global mutuo. Desde el punto de vista económico, el turismo es un importante generador de puestos de trabajo y revitalizador de economías, no solo nacionales sino también regionales y locales, estas últimas especialmente necesitadas de nuevos recursos y especialmente afectadas por el problema de la despoblación y del envejecimiento de la población.

Los principios fundamentales de la Ley son cuatro:

1) Ser conscientes de la importancia de construir una nación que sea un buen sitio para vivir, pero también un buen sitio para visitar, enriqueciendo así la vida de las personas

2) Promover los viajes a lugares de interés (viajes turísticos)

3) Poner de relieve la importancia de tener puntos de vista más globales

4) Resaltar la importancia de la coordinación entre las partes interesadas

Las partes interesadas son, en primer lugar, el Gobierno central, que debe elaborar y poner en práctica medidas integrales para lograr una nación de turismo. En segundo lugar, los gobiernos locales que deberán implementar medidas que aprovechen las características regionales y que persigan la cooperación más amplia entre los interesados. También la población debe comprender la importancia de promover que Japón sea una nación turística y asumir un papel positivo de desarrollo de los lugares con atractivos turísticos. Finalmente, la industria turística debe hacer esfuerzos para conseguir una nación turística.

¿Cuál es la razón de esta reforma tras más de cuarenta años sin modificar la legislación en este campo? Los motivos son muy claros en opinión de Isabel Handler y Ito Noriko ${ }^{3}$, que afirman que Japón tenía en esos años, una de las más ineficientes políticas dedicadas al turismo externo y que, además, se caracterizaba por la ausencia de una autoridad central en materia turística, por lo que había varias organizaciones y departamentos que presentaban iniciativas que giraban en torno a la promoción de Japón como destino turístico, pero sin una estrategia común que aunara los esfuerzos de todos los implicados hacia unos objetivos concretos y comunes.

\section{El Plan Nacional de promoción del turismo}

La nueva Ley señala la elaboración de un Plan nacional de promoción del turismo que sea el centro de la política fundamental para conseguir una nación turística, que seleccione los objetivos fundamentales, que recoja el proyecto del Gobierno para implementar las necesarias medidas sistemáticas y globales y, en general que cumpla con todo lo necesario para ser aprobado por el Gabinete. Se encarga de ello al MLIT y este primer paso, encargando la labor a un ministerio gubernamental como auto-

3 Handler, Isabel / Ito, Noriko, (2008): "Missed Connections: Japan Inbound Tourism Campaigns". En: Revista Encontros Cientificos, monográfico Tourism \& Management Studies, nº 4, pp. 50-60 (http://tmstudies.net/index. php/ectms/article/view/48/8), [Consulta: 24/2/2017]. 
ridad competente y central, creemos que al menos, diluye alguno de los problemas señalados por las autoras antes citadas en cuanto a la falta de una autoridad central que coordinase una estrategia común.

El 30 de marzo de 2012 se adopta por parte del Gabinete un "plan básico nacional de promoción del turismo"4 que abarca el periodo del año fiscal 2012 al 2016 y en el que el turismo se sitúa como uno de los pilares de la estrategia de crecimiento de Japón y como una contribución importante a la recuperación del país tras el Gran Terremoto del Este de Japón. A este respecto, hay que señalar que el tsunami de 2011 y el subsiguiente accidente de la central nuclear de Fukushima, reflejados en todos los medios de comunicación mundiales, por un lado fueron dañinos para la imagen de Japón como país turístico, esto es evidente, pero lo cierto es que también añadieron un nuevo atractivo a los viajes a este país, en el sentido de que en algunos casos se convirtieron en viajes de apoyo o de hermandad 5 .

El nuevo Plan, basado en las disposiciones del artículo 10.4 de la Ley de Turismo, define en sus cuatro capítulos una estrategia básica para la realización de una nación turística y señala el año 2016 como año clave, con unos objetivos a alcanzar y nuevos índices para controlar el logro de un alto "nivel de satisfacción" para los visitantes extranjeros a Japón. Para lograr los objetivos establecidos en el plazo fijado, el Plan prevé una serie de medidas a adoptar en esos 5 años con el objetivo de superar los problemas que rodeaban el turismo e impulsar el crecimiento de Japón.

El Plan lo constituyen muy variadas y abundantes medidas y objetivos a lograr, por lo que aquí nos centraremos específicamente en el turismo internacional que llega a Japón y en las medidas que intentan potenciarlo:

1. El Plan intenta que el turismo sirva como motor para que el país pueda recuperarse de los desastres, fijándose sobre todo en el Gran Terremoto del Este de Japón, aunque posteriormente a la aprobación del Plan ha habido otros desastres, dadas las características naturales del propio país: por ejemplo, en 2015 varios volcanes entraron en erupción en las prefecturas de Kagoshima, Nagano, Gumma, Kanagawa y Kumamoto. También en aquel año, el tifón 18 trajo inundaciones a las regiones de Kantō y Tōhoku y en abril de 2016 hubo un terremoto muy potente en Kumamoto. Junto con la agricultura, la silvicultura y la pesca, el Plan señala que el turismo es una industria clave en las áreas afectadas. Se intenta por tanto, que estos desastres no influyan en el desarrollo de la industria turística, que era uno de los temores principales tras $2011^{6}$. Hay que tener en cuenta que Japón, por ser un país en donde los

4 Véase el texto de este Plan en versión en inglés en Ministerio de Territorio, Infraestructuras, Transportes y Turismo, (página web), http://www.mlit.go.jp/common/000234920.pdf [Consulta: 24-2-2017].

5 Korstanje, Maximiliano, señala en su trabajo "Filosofía del desastre: el terremoto de Japón de 2011 y el viajeproducto", Nómadas. Revista Crítica de Ciencias Sociales y Jurídicas, no 34, 2012 (http://dx.doi.org/10.5209/ rev_NOMA.2012.v34.n2.40728) que el viaje planeado para 2012 a Japón por parte de la FCAJ (Fundación Cultural Argentino-Japonesa) fue organizado con antelación al accidente, pero tras lo ocurrido no se canceló, sino que se mantuvo pero con un sentido distinto, pues no se trató solo de un viaje de carácter cultural sino que se indica que "se constituye como un esfuerzo de hermandad para estar con ese otro común asumiendo los riesgos que eso implica".

6 El propio Plan señala los temores del Gobierno de que la marca Japón se viera comprometida por el desastre, por lo que se pensó que el turismo podría jugar un gran papel publicitario importante en la recuperación y la mejora de esta confianza (véase Introducción, p. 2 y 3 del Plan básico, en la página web del Ministerio, http:// www.mlit.go.jp/common/000234920.pdf). En este sentido, el Plan propone actividades turísticas que sirvan a 
ciudadanos conviven con tifones, volcanes, tsunamis, etc. es también un país muy preparado para afrontarlos ${ }^{7}$.

2. El Plan tiene en cuenta el hecho de que Japón se enfrentará a una importante disminución de su población en unos años y además, al aumento de su población envejecida y una disminución de su tasa de natalidad, por lo que el Plan indica la necesidad de buscar una "población de intercambio" y el turismo puede contribuir al crecimiento de la misma. El turismo es una industria estratégica integral, pues el negocio relacionado con ella es extremadamente grande, por lo que el Plan quiere impulsar el consumo en este campo, lo que contribuirá también a la creación de empleo e invitará a la inversión, lo que reforzará intensamente la economía de Japón.

En relación con la economía, Japón, con este Plan, pretende aprovechar la situación de la economía global: concretamente, el crecimiento económico en los países emergentes de Asia ha ayudado a aumentar el número de ciudadanos asiáticos que viajan al extranjero y uno de los destinos es Japón. Además, la deflación de los precios en Japón ha hecho que los consumidores internacionales sientan que viajar a Japón es relativamente barato. Las tarifas han bajado debido a la reducción en los recargos por combustible. También ha aumentado el interés por Japón como puerto de escala de los cruceros internacionales. Por otra parte, la declaración de la cocina tradicional japonesa

fines sociales, tales como las misiones de voluntariado y la comunicación continua con la población local. En este sentido, se trata de un nuevo concepto de turismo que suele denominarse turismo solidario o turismo social, que algunos especialistas (López-Guzmán Guzmán, Tomás / Millán VÁzquez de la Torre, Genoveva / Melián NAvArro, Amparo (2007), "Turismo solidario. Una perspectiva desde la Unión Europea”. En: Gestión Turística, 8, Valdivia (Chile), pp. 85-104, especialmente p. 88.) (http://mingaonline.uach.cl/pdf/gestur/n8/art07.pdf) definen como "aquel tipo de actividad económica en el que los procesos de desarrollo se realizan esencialmente en beneficio de las poblaciones directamente afectadas y ubicadas en Países en Vías de Desarrollo, y de acuerdo con dos premisas: primera, que el turismo minimice el impacto sobre el entorno, buscando conservar el patrimonio local, las culturas, las tradiciones, el medio ambiente, etc.; y segunda, que el turismo fortalezca las sociedades locales, gracias a dinámicas económicas autónomas". Un elemento adicional es la estrecha interrelación entre el turista y la población local, lo que en el caso japonés llevaría a la mejor comprensión de la situación en Fukushima, ya que el turista podría desempeñar algún tipo de trabajo dentro de la propia comunidad local. Este concepto es muy utilizado en España pero en estos casos los viajes son organizados no por agencias tradicionales de viajes, sino fundamentalmente por ONGs de ayuda al desarrollo.

7 Japón dispone de la más moderna tecnología en relación con estos temas: las localidades ubicadas en la costa, más propensas a sufrir tsunamis, son las mejor preparadas: cada hogar dispone de un sistema de alarma que permite a las autoridades locales comunicarse con los inquilinos en caso de amenaza; los caminos y otras vías de escape que conducen a terrenos elevados, con menor riesgo, tienden a estar claramente señalizados; muchas zonas disponen también de diques para contener el agua y algunas ciudades costeras cuentan con sensores que, conectados a las viviendas, cierran de forma automática las puertas para evitar que las olas penetren en el interior. Desde el terremoto en la ciudad de Kobe de 1995 las boyas cuentan también con sensores para predecir con al menos 30 minutos de antelación las amenazas. Por otra parte, desde la década de los 50 del siglo XX, los edificios en Japón se construyen cumpliendo determinados parámetros de seguridad muy exigentes, en los que se tienen en cuenta factores como los cimientos que se utilizan o dónde se distribuye el peso. Los pisos bajos son los que aguantan más peso y deben estar separados para que en caso de terremoto no se golpeen entre si. Existen guías para los ciudadanos en las que se detalla qué tareas concretas se deben llevar a cabo en caso de terremoto, tsunami, etc. (sin embargo, autores como CASADO Claro, Ma Francisca (2016): Japón en la encrucijada nuclear. Un estudio crítico de las implicaciones de la energía nuclear para la política de seguridad medioambiental de Japón tras el desastre de Fukushima, Tesis Doctoral dirigida por Antonio Marquina Barrio, Universidad Nacional de Educación a Distancia. http://e-spacio.uned.es/fez/eserv/tesisuned:IUGM-Mfcasado/ CASADO_CLARO_MariaFrancisca_Tesis.pdf [Consulta: 12/6/2017] son muy críticos con la preparación de Japón para los desastres nucleares y opina que se sigue estando mal preparado para responder de manera efectiva a este tipo de accidentes (ver esp. pp. 257 y 310 ). 
o washoku como patrimonio cultural inmaterial de la $\mathrm{UNESCO}^{8}$, la fama del fenómeno manga o la próxima celebración de los Juegos Olímpicos de 2020 son elementos de atracción para los turistas extranjeros. Pero no hay que olvidar que hay una serie de países en la zona que hacen una muy seria competencia al turismo japonés, por lo que Japón debe incrementar su nivel de competitividad.

El Gobierno ha tomado una serie de medidas favorables a la llegada de viajeros de otros países, como el aumento en el número de franjas horarias de salida y llegada en los aeropuertos internacionales, la reducción de las restricciones de visado para determinados visitantes extranjeros, la ampliación del ámbito de aplicación de las exenciones a los impuestos al consumo para los visitantes extranjeros, así como la mejora de los procedimientos CIQ99. Además se han potenciado actividades de promoción para atraer visitantes a Japón, como los esfuerzos para dar a conocer las estaciones del año en Japón (disfrutar del follaje del otoño — momiji-, de los paisajes nevados en invierno o apreciar las flores de cerezo en primavera - hanami-). Se han realizado esfuerzos para atraer visitantes extranjeros no sólo a la zona de Tokio y la llamada "ruta turística de oro", sino también a las zonas rurales en Japón. En concreto, se colocaron en las principales estaciones y en otras instalaciones en países extranjeros anuncios y spots para que los futuros visitantes conocieran los atractivos del mundo rural japonés. Se trata de un esfuerzo conjunto de la nación, los municipios, las empresas, los residentes, las organizaciones sin fines de lucro y otros actores del turismo, que deben hacer esfuerzos concertados para desempeñar sus respectivos papeles con el fin de que el turismo reconstruya la economía de Japón y las comunidades locales en el siglo XXI.

3. El Plan intenta una mejora de la comprensión mutua a nivel internacional, lograr que se tengan perspectivas más globales. Este punto está relacionado en el Plan con el hecho de que Japón quiere promover la imagen de país defensor de la paz internacional, tener un papel más influyente en el Consejo de seguridad de Naciones Unidas como miembro permanente y apoyar las actividades diplomáticas y de seguridad de Japón en el exterior ${ }^{10}$. El Plan quiere impulsar el intercambio internacional bilateral llevado a cabo por jóvenes y otros ciudadanos, cultivar los aspectos culturales de Japón que son aceptados en el mundo, animar a los extranjeros a mejorar su comprensión de Japón y difundir la importancia de acoger con beneplácito a los visitantes (en este sentido, se trata de poner de relieve el espíritu de omotenashi (hospitalidad japonesa). También se habla en el Plan de atraer a personas y empresas del extranjero a través del soft power de Japón, arraigado en la sabiduría acumulada a través de su historia, así como la potencia de su industria.

8 Véase sobre esta cuestión el interesante trabajo de BARREIROs, Beatriz (2014): "Japón ante el patrimonio inmaterial: El shochu y washoku en las Convenciones de la UNESCO y en la Organización Mundial del Comercio" En: Tirado, Carmen (dir.). Japón y Occidente: estudios comparados. Zaragoza: Prensas Universitarias, pp. 99-112.

9 El Código CIQ se aplica a los buques, independientemente de sus dimensiones, incluidos los de arqueo inferiores a 500 TRB (en castellano, V toneladas de registro bruto), dedicados al transporte de cargas a granel de productos químicos peligrosos o sustancias nocivas líquidas (SNL) que no sean petróleo ni productos inflamables análogos.

10 Véase en este sentido Tirado, Carmen (2013): Japón ante del Derecho Internacional. Cizur Menor (Navarra): Thomson Reuters Anazadi, especialmente el capítulo dedicado a Naciones Unidas, pp. 204-214. 
4. El Plan, finalmente, señala la necesidad de estabilización y mejora de la vida de las personas, es decir, el turismo hace la vida agradable y rica y puede cambiar a la sociedad japonesa, que se dice que es introvertida y ofrecer a las personas oportunidades de aprendizaje. Para lograr este objetivo, el Plan pretende diseñar nuevos estilos de viaje para hacer el turismo más atractivo y establecer un entorno en el que las personas, especialmente los jóvenes y los ciudadanos de la tercera edad, estén más interesados en el turismo y realmente puedan viajar.

Esta serie de objetivos y medidas aplicables al turismo internacional que llega a Japón no surgen en un panorama sin legislación; al contrario, lo propuesto en el Plan de 2012 tenía muy en cuenta la situación anterior y, concretamente, las propuestas presentadas por el Plan de 2007 y sus resultados. Para tener, por tanto, una visión realista de las razones del Plan que abarca el período 2012-2016, hay que tener muy en cuenta los resultados del Plan anterior, que seguidamente estudiamos.

\section{Los resultados del Plan anterior}

En el Plan se señalaban una serie de objetivos que se contemplaban en el Plan anterior, aprobado por el Gabinete en junio de 2007, centrados en objetivos cuantitativos que debían haberse cumplido en 2010, aunque la mayoría de estas cifras no pudieron cumplirse por diversas causas, fundamentalmente centradas en la crisis económica:

Aumentar el consumo de viajes domésticos: el objetivo era llegar a los 30 billones de yenes partiendo de la cifra de 2009 que era de 25.5 billones de yenes, pero no se logró el objetivo, sobre todo debido a la crisis económica y al descenso de visitantes chinos a causa de la crisis de las Senkaku en $2010^{11}$.

- Aumentar el número de visitantes extranjeros: el objetivo era llegar a los 10 millones en 2010. Aunque el número de visitantes extranjeros en 2007 era de 8.35 millones, debido a la crisis global esta cifra bajó a 6.79 en 2010 y el terremoto de 2011 no mejoró la situación.

- Aumentar el número de conferencias internacionales celebradas: el objetivo era lograr un aumento igual o mayor del $50 \%$ partiendo de la cifra de 2005 de 168 conferencias internacionales celebradas. El objetivo se hubiera conseguido en 2010 con 252 conferencias celebradas, pero realmente se celebraron 741 superando con creces la meta fijada. Las razones de ese incremento, que convierten a Japón en el país número uno de Asia en el acogimiento de conferencias internacionales, hay que situarlas, en primer lugar,

11 En cuanto a esta crisis, las islas Senkaku, según denominación nipona, o Diaoyu, según China (Taiwán también las disputa y las denomina Diaoyutai) son un pequeño archipiélago situado en el Mar de China Oriental sobre el cual, al menos de momento y de facto, tiene el control efectivo Japón, pero sobre el que hay una disputa territorial muy importante, que ha causado serios problemas en las relaciones diplomáticas entre China y Japón, principalmente. Sobre esta cuestión véase el apartado dedicado a esta cuestión en Ibid., pp. 183-191. Más recientemente, analiza también este conflicto territorial Fravel, M. Taylor (2016): "China's Assertiveness in the Senkaku (Diaoyu) Islands Dispute", Massachusetts Institute of Technology (MIT) - Department of Political Science, June 1, Research Paper $\mathrm{n}^{\circ}$. 2016-19 (https://papers.ssrn.com/sol3/papers.cfm?abstract_id=2788165\#\#) [Consulta: 24/2/2017]. 
en el hecho de que el número de conferencias internacionales celebradas en Asia está aumentando debido a que las sociedades académicas asiáticas están creciendo con el progreso constante del crecimiento económico asiático y que las conferencias nacionales se están internacionalizando. La cifra aumentó considerablemente especialmente en 2010, en parte debido a que se celebraran un gran número de conferencias relacionadas con la APEC y la COP10 12 .

- Aumento del número de noches por persona en viajes nacionales: el objetivo era llegar a 4 noches por persona, pero solo se consiguió llegar a 2,12 noches por persona.

- Aumentar el número de viajeros japoneses a ultramar: partiendo de la cifra de 15, 9 millones en 2008 el objetivo era llegar a 20 millones en 2010, pero solo se pudo conseguir la cifra de 16.64 millones.

Durante el período del Plan Básico anterior, se promovieron varias medidas y se estableció la Ley de Promoción de Visitas y Estancias Turísticas a través del Desarrollo de Regiones Turísticas (Ley 39/2008). En consecuencia, se produjeron algunos resultados, entre ellos el mantenimiento y mejora de las Zonas Turísticas, el mantenimiento y mejora de las pistas de los aeropuertos internacionales Haneda, Narita y Kansai, la mejora de facultades y departamentos relacionados con el turismo en las universidades japonesas, así como la celebración de conferencias internacionales y otros eventos, y finalmente, la minoración de los requisitos para la expedición de visados turísticos a los ciudadanos chinos.

\section{Los objetivos de futuro del Plan de 2012}

Una vez señalada la situación de partida con debe decir: los resultados obtenidos por el Plan de 2007, podemos abordar la propuesta de 2012 y evaluarla. En el Plan se proponen una serie de objetivos en relación con la mejora de la base del turismo ${ }^{13}$, de los que vamos a comentar específicamente los centrados en el turismo internacional.

Mientras que cuando comenzó la campaña Visit Japan en $2003^{14}$, los mercados a los que se dirigía esta campaña eran principalmente cinco: Estados Unidos, Corea

12 La APEC (http://www.apec.org/) es un foro multilateral creado en 1989, con el fin de consolidar el crecimiento y la prosperidad de los países del Pacífico, que trata temas relacionados con el intercambio comercial, coordinación económica y cooperación entre sus integrantes. Japón es uno de los países miembros. En cuanto al COP 10 (https://www.cbd.int/cop10/) es la Conferencia de Partes (COP) del Convenio sobre diversidad biológica, que se celebró en 2010 en Nagoya.

13 El Plan señala además una medida de carácter general que es la reforma de la Organización Nacional de Turismo de Japón en el plano administrativo y esto implica una nueva denominación, "Japan Tourim Agency" conocida por sus siglas JTA y una nueva naturaleza jurídica, pues esta nueva organización forma parte de las Agencias Administrativas Independientes, las llamadas en japonés Dokuritsugyōsei Hōjin. Es una nueva corporación que se establecerá de acuerdo con la normas aprobadas por el Gabinete el 20 de enero de 2012 y a la que se transfieren las funciones de la actual Organización Nacional de Turismo de Japón. Las Dokuritsugyōsei Hōjin, en inglés denominadas Incorporated Administrative Agency (IAA) forman parte de una iniciativa del Gobierno japonés que se articula en una reforma legislativa basada en la idea de que en el sector público, debe estar separada la planificación de la ejecución, de manera que en el caso de la JTA, se trata de una agencia externa del Ministerio de Territorio, Infraestructuras, Transportes y Turismo.

14 Véase Visit Japan Campaign en la web de Japan Tourim Agency (https://www.mlit.go.jp/kankocho/en/inbound/ vjc.html) con los datos de 2003 hasta 2010. 
del Sur, China, Taiwán y Hong Kong, la situación actual ha evolucionado de manera importante pues los mercados se han ampliado a algunos países europeos: Francia, Alemania, Reino Unido y Rusia, así como a Australia, Canadá, Singapur, Tailandia, India y Malasia, en total quince países cuyos nacionales fueron los que mayoritariamente visitaron Japón. En 2010 el dato era de 8,61 millones de visitantes, todavía lejos del objetivo que se pretendía de los 10 millones de visitantes extranjeros. Actualmente esa cifra se ha ido incrementando a 18 millones en 2016 y el nuevo objetivo es de 25 millones de visitantes extranjeros para 2020, por lo que la estrategia Visit Japan debe acomodarse a los gustos de los visitantes extranjeros y ser más dinámica y eficaz, dirigiéndose no sólo a los mercados a los que se ha dado prioridad hasta ahora, sino también a los mercados de los países del sudeste asiático y otras regiones, donde se espera un rápido crecimiento de la clase alta y media. Para ello, se proponen medidas como promocionar destinos dentro de Japón distintos de la llamada "ruta dorada" o utilizar a estudiantes extranjeros como una especie de embajadores de turismo para Japón, que pueden convertirse en visitantes que repiten este destino.

También es necesario resolver varios problemas relacionados con el idioma, los gastos de viaje, la administración de inmigración, etc. e invertir esfuerzos nacionales en mantener y mejorar la cooperación entre Ministerios y agencias, gobiernos locales y empresas privadas para facilitar el viaje y la estancia de los visitantes en Japón.

El Plan indica, acertadamente, que no solo hay que tener en cuenta el número de visitantes extranjeros (el objetivo fijado de 18 millones para 2016 era muy ambicioso y se ha logrado, pero no es el único), también es importante el efecto económico que dejan estos turistas y, a este respecto, se toman medidas para prolongar la estancia de los visitantes extranjeros en Japón y aumentar su consumo e invitar a los viajeros a un consumo diario promedio alto.

El Plan menciona el turismo $\mathrm{MICE}^{15}$, que se está fijando en los últimos años en los países asiáticos y lo cierto es que en Japón, las actividades MICE han sido iniciativas principalmente de gobiernos locales, agencias de convenciones, empresas privadas y otras entidades individuales interesadas. Sin embargo, esto es a veces insuficiente en comparación con los países competidores. La nación necesita apoyar sus esfuerzos para celebrar actividades MICE para mejorar su competitividad internacional.

Por otra parte, también es necesario que se incremente y se facilite el viaje a los japoneses que quieren salir al extranjero pues esto ayudará a mejorar la comprensión de los asuntos internacionales por parte de los japoneses, contribuirá al desarrollo de las actividades turísticas en los países en desarrollo y complementará la diplomacia intergubernamental con la llamada soft diplomacy ${ }^{16}$. Puede incluso contribuir a la ex-

15 El turismo MICE no es otra cosa que el acrónimo en inglés para Meetings, Incentives, Conventions and Exhibitions, es decir, el turismo de reuniones, incentivos, congresos y exposiciones; hace referencia al turismo de negocios como un conjunto de corrientes turísticas cuyo motivo de viaje está vinculado con la realización de actividades laborales, de ocio, profesionales y/o asociativas a través de la realización de reuniones de negocio, congresos, convenciones, viajes de incentivo y otras reuniones similares a estas (jornadas, presentaciones de producto, conferencias, simposios, foros, seminarios, cursos...) convocados con diferentes propósitos y magnitudes. https://turismomice.wordpress.com/introduccion/) [Consulta: 24/2/2017].

16 En este sentido véase Chen, Yu-Wen / Duggan, Niall (2016): "Soft Power and Tourism: A Study of Chinese Outbound Tourism to Africa". En: Journal of China and International Relations, vol. 4, n'. 1, pp. 45-66 (https:// journals.aau.dk/index.php/jcir/article/view/1514/1239 [Consulta: 24/2/2017]. Aunque centrado en otra zona geográfica, hace referencia al concepto de soft power en relación con el turismo: "Soft power is developed and maintained over time through such medium as public diplomacy, the export of culture, and people-to-people exchanges”. También WatanABE, Yasushi : "Japanese Soft Power and Influential Foreign Policy. From Japonism 
pansión del turismo receptivo, mediante el aumento de los intercambios internacionales bilaterales con países extranjeros (lo que se conoce como turismo bidireccional).

\section{Las medidas para mejorar la base del turismo centradas en el turismo internacional}

Teniendo en cuenta los ambiciosos objetivos señalados antes en cifras (aumento del número de visitantes extranjeros a Japón, incremento del nivel de satisfacción de estos visitantes extranjeros, incremento del número de conferencias internacionales celebradas en Japón y, finalmente, elevación del número de japoneses que viajan al extranjero), el Plan básico promueve una serie de medidas referidas a:

\subsection{La expansión y mejora del turismo internacional:}

a) Implementar las promociones de la campaña Visit Japan. Con el fin de atraer a visitantes extranjeros a Japón, además de realizar promociones principalmente en los cinco mercados priorizados, es esencial expandir los objetivos a viajeros de clase media en el sudeste asiático y otros países emergentes, zonas donde se espera un notable crecimiento económico en el futuro, así como los mercados europeos, estadounidenses y australianos, donde es más probable que los viajeros planifiquen estancias más largas y estén más dispuestos a hacer un gasto importante en servicios turísticos. En este sentido, el Plan señala la necesidad de hacer esfuerzos más intensos con métodos más dinámicos, fuera del marco tradicional de promoción, así como el establecimiento de All-Japan, un marco de cooperación más estrecha entre los ministerios y organismos competentes, no limitado a la Agencia Japonesa de Turismo y la Organización Nacional de Turismo de Japón, e incluyendo las misiones diplomáticas en el extranjero.

b) Mantenimiento integral y mejora de las instalaciones de transporte y de las organizaciones de transporte necesarias para aumentar los turistas que visitan Japón.

c) Promoción de las visitas de turistas extranjeros mediante la transmisión focalizada y efectiva del atractivo del turismo en Japón, suministro de información sobre los gastos necesarios para el transporte, alojamiento y otros relacionados con las visitas guiadas en Japón, así como mejora de los procedimientos necesarios para que los turistas extranjeros entren y salgan de Japón, mejora de los servicios de intérprete y guía, establecimiento de nuevos marcos y organizaciones para la aceptación de turistas extranjeros, etc.

\subsection{Lograr un mayor nivel de satisfacción de los visitantes extranjeros ${ }^{17}$ :}

a) Creación de zonas turísticas atractivas para los visitantes, tanto de dentro como de fuera del país (marcado de zonas turísticas en folleto y demás pro-

to Neo-Japonism", Centro per gli Studi di Politica Estera e Opinione Pubblica, Universidad de Milán, Paper, (http://www.polestra.com/public/files/papers/paper\%20watanabe.pdf [Consulta: 24/2/2017], que hace referencia justamente a los esfuerzos de Japón en crear una nación turística como claro ejemplo de soft power.

17 El Plan propone que para el año 2016, la proporción de los encuestados extranjeros que contestan "Muy satisfecho" en las encuestas sobre tendencias de consumo sea del $45 \%$ y la proporción de los encuestados que contestan "Sin duda, quiero volver de nuevo" del 60\%. 
paganda, amplia cooperación entre los diferentes niveles implicados —nacional, regional, local-)

b) Aumento de la competitividad internacional de la industria turística: Garantizar la prestación de servicios de alta calidad se considera esencial, además de mantener y mejorar las instalaciones relacionadas con el turismo, incluidas las instalaciones de alojamiento, los servicios de alimentación y las instalaciones de orientación, así como las instalaciones públicas en general. Se señala como incentivo turístico la promoción y desarrollo del turismo cultural, histórico, medioambiental... En este sentido, otra de las medidas mencionadas por el Plan habla de promocionar nuevos campos de turismo, como el ecoturismo, el turismo ecológico, el turismo cultural, incluso el turismo industrial, el turismo de salud, el turismo deportivo y otras nuevas opciones de turismo que utilizan la moda, la alimentación, el cine, la animación, los bosques de montaña, las flores, etc. También se cultivarán otras nuevas demandas turísticas (estímulo de la demanda de viajes de jóvenes, promoción del turismo de estancias prolongadas, mejora del atractivo de los cruceros y promoción del turismo vinculado a la atención médica y a la salud).

c) Mejora del trato a los turistas extranjeros favoreciendo su entrada y salida del país, servicios de intérprete, guía, etc. En este sentido se propone dar todas las posibilidades al personal de la industria turística para mejorar su formación en relación a cómo tratar a los visitantes extranjeros ${ }^{18}$, así como la mejora de las instalaciones relacionadas con el turismo y la presentación de la cultura tradicional japonesa en cuanto a su gastronómica, forma de vida, productos regionales, etc.

d) Mejora de la comodidad de los turistas, facilitando los accesos a ancianos y discapacitados, suministrando información turística a través de la tecnología de la información y de la comunicación.

\subsection{Incremento del número de conferencias celebradas}

Aquí destaca la necesidad de potenciar la competitividad internacional en el ámbito MICE, además de otras medidas ya mencionadas en otros apartados como mejora de los transportes, facilitación de la entrada y salida del país para los visitantes extranjeros que acuden a conferencias internacionales, etc.

El objetivo era que en 2016 se llegase a un aumento del 50\% o más de las conferencias internacionales celebradas y, por tanto, que Japón se convirtiera en el primer país anfitrión de conferencias en Asia. Es verdad que el número anual de conferencias internacionales ha ido en aumento en todo el mundo. Alrededor de la mitad de todas las conferencias internacionales celebradas en 2014 tuvieron lugar en Europa, donde tienen su sede muchas instituciones internacionales y sociedades académicas. Sin embargo, el número de conferencias internacionales en la región de Oriente Medio y de Asia Pacífico y en América del Sur está creciendo rápidamente debido a la alta tasa de crecimiento económico de estas regiones. El número de conferencias

18 Amadeo Jensana señalaba en 2010 que menos de un 5\% de japoneses hablaba inglés, lo que se traduce en el mundo empresarial en dificultades de comunicación, aunque esto depende del tamaño de la empresa, edad de los interlocutores, sector de negocios, etc. Véase Jensana TANEHASHI, Amadeo (2010): "Factores culturales y negocios en Japón”. En: Información Comercial Española, ICE: Revista de economía, $\mathrm{n}^{\circ} 856$ (Ejemplar dedicado a: Factores culturales e internacionalización de la empresa y la economía), pp. 79-88, esp. p. 86. 
internacionales que Japón acogió en 2014 fue de 337, el séptimo país del mundo (España es el $3^{\circ}$ ), sin embargo el dato no es bueno, pues el porcentaje de participación de Japón en estos eventos en relación con años anteriores ha decrecido, puesto que la competencia con otros países de la zona es dura (sobre todo con China, Singapur, Australia y Corea del Sur). Si bien en el Plan anterior éste era el único de los puntos en que las expectativas se habían cumplido de manera satisfactoria, lo cierto es que en este Plan es uno de los aspectos en los que se deben hacer esfuerzos de mejora.

En la "Estrategia de Revitalización de Japón: Japan is back"19 aprobada en una reunión de Gabinete en 2013, se señalaba como objetivo la consolidación como país sede de las conferencias internacionales en Asia en 2030. Japón necesita reforzar su capacidad de atracción de conferencias internacionales con 1.000 o menos asistentes, es decir, conferencias pequeñas o medianas, que es donde le ganan sus competidores tanto asiáticos como occidentales. Además, también debe mantenerse como polo de atracción de conferencias y eventos internacionales, por lo que en ese sentido el logro de los Juegos olímpicos de 2020 ha sido considerado como un gran éxito.

\subsection{Incremento del número de japoneses que viajan al extranjero:}

a) Promoción de las reformas para días libres ${ }^{20}$ : las discusiones hasta ahora sobre las reformas legislativas en materia de días libres han servido para reflexionar de manera seria sobre la distribución entre tiempo de trabajo y de ocio en el país nipón. También parece que a raíz del desastre del terremoto en el este del país, algunas personas han revisado su estilo de vida. En estas circunstancias, el Plan propone esfuerzos para mantener y mejorar el ambiente de trabajo, para que los trabajadores puedan dejar fácilmente un puesto de trabajo y aceptar otro nuevo y que, además de que esto no suponga una tragedia en la vida de la persona, sirva para cambiar la concepción de los trabajadores japoneses sobre el tiempo libre. Esta mayor flexibilidad en el uso del tiempo de los trabajadores japoneses puede animar a que realicen viajes al extranjero que, normalmente, requieren de una mayor disponibilidad temporal. También se propone continuar estudiando la implementación real del Plan para distribuir las vacaciones largas del año en momentos diferentes para cada región para que las vacaciones se dispersen en distintos momentos del año, teniendo en cuenta también los efectos en la vida de la

19 Véase el texto en versión inglesa de esta Estrategia en la página web de la residencia oficial del Primer Ministro japonés: http:/www.kantei.go.jp/jp/singi/keizaisaisei/pdf/en_saikou_jpn_hon.pdf [Consulta: 27/2/2017] especialmente, pp. 125 y 126. En estas medidas se involucran la Agencia Japonesa de Turismo, la Organización Nacional de Turismo de Japón (JNTO), el Ministerio de Economía, Comercio e Industria y la Organización Japonesa de Comercio Exterior (JETRO), que trabajan juntos desde la adopción del Programa para crear un plan de acción conjunto y aumentar el número de visitantes extranjeros.

20 Es sabido que el número de días libres de los trabajadores japoneses es menor que el de los trabajadores de la mayor parte de los países europeos e igual que el de los estadounidenses. En este sentido, es importante reformar la legislación laboral para que los japoneses puedan disfrutar de los suficientes días libres de manera consecutiva para que puedan plantearse realizar viajes al extranjero. En este sentido véase: OKABE, Fuminobu (2016): "La reforma laboral del Gobierno Abe. Su incidencia en la vida y derechos de los trabajadores japoneses". En Tirado, Carmen / Barberán, Francisco (coords.). Los derechos individuales en el ordenamiento japonés. Cizur Menor (Navarra): Thomson Reuters Aranzadi, pp. 223-233, así como Matsumoto, Alberto Shunji (2015): “Contratación laboral”. En: BArberÁn, Francisco/ Kuroda, Kiyohiko / OKABE, Fuminobu (coords.), Introducción al Derecho japonés actual. Cizur Menor (Navarra): Thomson Reuters Aranzadi, pp. 605-632. 
gente del desastre de 2011, las actividades económicas, así como el estado del consenso público.

b) Promoción de intercambios internacionales mutuos, a través de proyectos bilaterales de intercambio turístico, concurrencia a ferias de turismo con presentaciones mutuas entre países, etc. Especialmente se señala la importancia de promocionar el turismo entre China, Corea del Sur y Japón ${ }^{21}$, tres países muy vinculados histórica y culturalmente.

c) Mejorar la comprensión de las personas sobre la importancia del turismo, evitando el problema "zero-travel demographic" es decir, las personas que no realizan ningún viaje en todo un año, promover los viajes de "babyboomers" 22 y jóvenes. Respecto a este último grupo, los jóvenes, el Plan ya habla de un programa específico que actualmente se está poniendo en marcha por parte de la Embajada japonesa en España: es el Programa Working Holiday, que consiste en acuerdos bilaterales que Japón comenzó a negociar en 1980 con el fin de brindar a los jóvenes de los países implicados oportunidades de entender la cultura y los diferentes estilos de vida al quedarse en el país ${ }^{23}$.

El objetivo en este punto era lograr que 20 millones de viajeros japoneses salieran al extranjero para el año 2016. Sin embargo, los datos de 2015 fueron muy negativos, pues la disminución en el número de japoneses que viajan al extranjero es clara. Un ejemplo palmario es que ya solo en los destinos más visitados (China, Corea del Sur y Hong Kong), el número de visitantes japoneses disminuyó en 700.000 personas ${ }^{24}$.

21 En 2006 se produce la primera reunión de Ministros Japón-China-Corea del Sur para ampliar el turismo dentro y fuera de los tres países y fortalecer la cooperación entre ellos. Esta reunión se celebra cada año y en la $5^{\mathrm{a}}$ reunión, celebrada en 2010, se establece el objetivo de 26 millones de viajeros entre los tres países para 2015, objetivo que se refleja en la Declaración conjunta aprobada en dicha Cumbre. En la $6{ }^{a}$ Cumbre en 2011 se propone fortalecer la cooperación entre los tres países para la gestión de crisis en el momento de un desastre, etc. y se plasma también en una Declaración Conjunta, en la que se señala también la promoción de rutas de oro en Japón, China y Corea, con el fin de ampliar los intercambios turísticos entre ellos.

22 Los "Baby Boomers" son todos aquellos que nacieron entre los años 1945 y 1964, es decir, a aquellos que nacieron tras el período de la Segunda Guerra Mundial, ya que se produjo un verdadero baby boom en países como Estados Unidos, Canadá, Nueva Zelanda y Australia. Estas personas se dice que son las que hoy tienen el mayor poder adquisitivo, puestos de responsabilidad y poder en las empresas, etc. y son, por tanto, a las que hay que captar mediante estrategias de marketing modernas y adaptadas a sus gustos e intereses (al respecto véase MitAni, Naoki (2008): "Mandatory retirement of baby boomers and human resource strategies of business firms". En: Japan labor review, Vol. 5, nº. 2, pp. 7-35, (Ejemplar dedicado a: Employment of older persons), así como Corredor Lanas, Patricia (2007): "Baby boomers, el tesoro transparente. Toda una generación de alto poder adquisitivo parece ser invisible para la mayoría de anunciantes y agencias". En: Anuncios: Semanario de publicidad y marketing, $\mathrm{n}^{\circ} .1209$ (OCT 8), pp. 26-27, en donde se pone de manifiesto la necesidad de que el mundo empresarial, en general, preste atención a este grupo poblacional.

23 Los programas Working Holiday actualmente existen entre Japón y 16 países: Australia desde 1980, Nueva Zelanda desde 1985, Canadá desde 1986 y seguidamente Corea del Sur, Francia, Alemania, Reino Unido, Irlanda, Dinamarca, Taiwán, Hong Kong, Noruega, Portugal, Polonia, así como Eslovaquia y Austria desde 2016 (véase la página web del Ministerio de Asuntos Exteriores de Japón, http:/www.mofa.go.jp/j_info/visit/w_holiday [Consulta: 24/2/2017]. Los participantes pueden, durante sus vacaciones en Japón, realizar trabajos de carácter esporádico o temporal con un visado especial dentro del Programa, con el fin de completar sus recursos económicos de viaje. Últimamente, el número anual de jóvenes que obtienen visados de trabajo para vacaciones en Japón asciende a casi 10.000 .

24 Gómez Aragón indica las dificultades que para la industria turística occidental implica el turismo de los japoneses: "La idiosincrasia particular del pueblo japonés ha impuesto una serie de requisitos específicos a la industria turística que hoy día son bien conocidos por todas las empresas que forman parte de la cadena de servicios que trabaja con estos clientes", véase Gómez Aragón, Anjhara (2014): "El turismo en las relaciones entre Japón y Occidente". En: Gómez Aragón, Anjhara (ed.). Japón y su relación con Occidente. Conmemo- 
Si Japón quiere ser una nación turística también debe potenciar este tipo de viajes, pues de este intercambio pueden surgir nuevas oportunidades de negocio y de enriquecimiento social.

\section{Conclusiones}

El balance es positivo, en general, pues las medidas presentadas en este Plan básico y puestas en marcha por las autoridades, están teniendo gran éxito en la mayor parte de los ámbitos propuestos. En nuestra opinión son muy acertadas especialmente las que facilitan a los turistas el acceso al país, como las medidas en relación con los visados turísticos, la formación del personal dedicado al turismo en lo que se refiere al trato de extranjeros, dominio de idiomas como inglés, español, que son mayoritariamente hablados en el mundo, así como las medidas tendentes a abrir el abanico de posibilidad turísticas a campos nuevos, como el turismo ecológico o el turismo relacionado con la salud, en donde Japón tiene mucho que ofrecer todavía.

Japón es un país con muchos atractivos turísticos, de manera que las grandes empresas turísticas de países como España o Francia pueden tener interés en establecerse allí y realizar inversiones importantes en Japón, no solo en hoteles sino también en vender circuitos turísticos para nacionales de esos países que quieren ir a Japón de la mano de sus propios nacionales, evitando subcontratar empresas japonesas que atiendan al turista al llegar a Japón. Sin embargo, Japón no es un país de gran potencial como receptor de inversiones extranjeras: según el Informe sobre las inversiones mundiales de 2015, Japón ocupa el décimo tercer lugar en la clasificación de las economías más atractivas para las compañías trasnacionales en el período 2015-2017, lo que no casa con su posición de tercera potencia económica en el mundo. El atractivo potencial de Japón para las inversiones extranjeras es muy fuerte en comparación con otros países del mundo, pero los resultados en cuanto a recepción de inversiones son débiles y los obstáculos de orden lingüístico junto con las preocupaciones sobre la contaminación del medio ambiente y las condiciones sanitarias provocadas por la situación de la central nuclear Fukushima podrían frenar las inversiones extranjeras en el futuro. Pero quizás el mayor obstáculo es la propia cultura de negocios japonesa, altamente aislada, que hace que las empresas japonesas tiendan a negociar mucho más con socios nacionales o ya conocidos, lo que frena la entrada de nuevos socios o de países diferentes de los habituales (los principales inversores en Japón son Estados Unidos, Países Bajos, Francia, Singapur y Reino Unido).

Sería interesante añadir al Plan algunas medidas que no se mencionan específicamente y que son interesantes para turistas europeos y americanos especialmente, por ejemplo, ampliar las posibilidades de pago con tarjeta de crédito (como es sabido, Japón es un país con un alto grado de seguridad ciudadana, por lo que normalmente los japoneses utilizan el dinero en efectivo en sus intercambios cotidianos en mayor medida de lo que lo hacen los ciudadanos en otros países, donde es más usual el pago con tarjetas), barrera que en los últimos años se ha ido desvaneciendo, igual que las barreras en el uso de la telefonía móvil, que también han desaparecido prácticamente con la existencia de aplicaciones como WhatsApp o line.

ración de los 400 años de relaciones España-Japón. Sevilla: Universidad Internacional de Andalucía, pp. 19-58, especialmente p. 30. 
Algunas medidas deben reforzarse, ya que los resultados no son especialmente satisfactorios, por una parte el número de turistas japoneses que sale al extranjero, pues en este campo las cifras propuestas por el Plan y las reales difieren; por otra parte las relativas a la celebración de conferencias y eventos internacionales, lo que llama la atención, pues Japón se distingue por un alto nivel de educación universitaria y es una gran potencia en la investigación, lo que debería hacer que fuera un foco importante de encuentros científicos y también empresariales. Puede perjudicar a Japón no solo la competencia de países vecinos que en los últimos años han potenciado ese aspecto, sino también el hecho de que se trate de un país geográficamente más inaccesible que otros (su situación insular es determinante) o las preocupaciones de seguridad en el plano sanitario, alimentario, etc. a raíz de del desastre de 2011. Sin embargo, creemos que esta situación se va a revertir claramente con la celebración de los juegos olímpicos de 2020, evento mundial para el que Japón se está preparando especialmente con medidas interesantes, como la traducción de símbolos y anuncios en lugares públicos (por ejemplo, los lavabos para hombres y mujeres en estaciones, trenes, museos, etc. evitando los ideogramas) o la salida al mercado de un traductor instantáneo en tiempo real llamado "ili", que no necesita internet, se está comercializando ya para inglés, japonés y chino y, según se dice en su publicidad, está especialmente diseñado para viajeros. 